\title{
СПЕЦИФИКА ПОСТРОЕНИЯ СЕТЕВОЙ МОДЕЛИ СОЗДАНИЯ СИСТЕМЫ МЕНЕДЖМЕНТА КАЧЕСТВА В МУЛЬТИСЕРВИСЕ ДЛЯ ПРЕДПРИЯТИЙ БЫТОВОГО ОБСЛУЖИВАНИЯ
}

\author{
(C) 2021 Домнин Антон Дмитриевич \\ аспирант, Высшая инженерно-экономическая школа \\ Санкт-Петербургский политехнический университет Петра Великого (СПбПУ), \\ Россия, Санкт-Петербург \\ E-mail: domnin_a@mail.ru
}

(c) 2021 Родионов Дмитрий Григорьевич

доктор экономических наук, профессор, Высшая инженерно-экономическая школа

Санкт-Петербургский политехнический университет Петра Великого (СПбПУ), Россия, Санкт-Петербург

E-mail: dmitry.rodionov@spbstu.ru

\section{(c) 2021 Конников Евгений Александрович}

кандидат экономических наук, доцент, Высшая инженерно-экономическая школа

Санкт-Петербургский политехнический университет Петра Великого (СПбПУ),

Россия, Санкт-Петербург

E-mail: konnikov.evgeniy@gmail.com

Сфера бытовых услуг является крайне дифференцированной с точки зрения качественных свойств оказываемых услуг. Несмотря на относительную универсализацию, обеспечиваемую автоматизацией основных производственных процессов, сервисная составляющая данных услуг обеспечивает комплексность эффекта качества. Данная специфика порождает необходимость формирования системы менеджмента качества в мультисервисе для предприятий бытового обслуживания. Данный процесс был ранее детально рассмотрен в рамках статьи [5], однако трансформация внешней среды потребовала уточнения как приведенных в исследовании экспертных оценок, так и разработки уникального подхода к оценке ожидаемого времени составных работ. Таким образом, целью данного исследования является развитие сетевой модели создания системы менеджмента качества в мультисервисе для предприятий бытового обслуживания, представленной в статье [5].

Ключевые слова: бытовое обслуживание населения, бытовые услуги, сетевая модель, менеджмен качества

Модель менеджмента качества является комплексным и многомерным объектом, крайне дифференцированным с точки зрения процесса формирования. Однако, могут быть выделены следующие универсальные принципы, определяющие базу процесса построения данной модели $[3,7,11,13]$ :

- «Принцип ориентации на потребителя предполагает изучение потребностей (запросов) потребителей, их интересов и покупательной способности. Данный принцип предполагает разработку стратегии качества услуг, основанной на опережающем знании интересов потребителей» $[2,4,6,13]$.

- «Принцип лидерства руководителя означает, что стратегия качества формируется при определяющей роли руководителя в принятии основополагающих решений» $[1,8,13]$.

- «Принцип вовлечения работников требует участия каждого из сотрудников фирмы в создании качественной услуги на всех этапах его жизненного цикла» [13].

- «Принцип процессного подхода устанавливает, что желаемый результат более эффективен, когда деятельностью по созданию услуги и соответствующими ресурсами управляют как процессом» [13].

- «Принцип системного подхода к менеджменту означает, что результативность и эффективность оказания услуг достигается за счет подхода к менеджменту как к менеджменту взаимосвязанных процессов» [13]. 
- «Принцип постоянного улучшения требует рассматривать непрерывное совершенствование деятельности фирмы как неизменную ее цель» [13].

- «Принцип принятия решений, основанных на фактах, задает ориентацию на поиск эффективного решения на основе привлечения фактов, статистики, использования обоснованных методов анализа» $[12,13]$.

- «Принцип взаимовыгодных отношений с поставщиками гласит, что фирма и ее поставщики взаимозависимы, и отношения взаимной выгоды повышают способность обеих сторон создавать ценности» [13].

Специфика системы менеджмента качества бытовых услуг в мультисервисе определяет потенциальную эффективность использования методология сетевого планирования для построения модели координации межорганизационных взаимодействий. Данный специфика был ранее детально рассмотрена в рамках статьи [5], однако трансформация внешней среды потребовала уточнения как приведенных в исследовании экспертных оценка, так и разработки уникального подхода к оценке ожидаемого времени составных работ. Таким образом, в рамках данной статьи производится реформирование модели, представленной в статье [5]. Первичным этапом базовой методологии является определение содержания работ, необходимых для организации системы менеджмента качества. В соответствии со спецификой, представленной в статье [5] можно определить следующее содержание работ при создании бытового мультисервиса как организационной формы объединения предпринимателей для обеспечения качественных бытовых услуг:

- Разработка положения о бытовом мультисервисе. Данная работа является первичной, и алгоритмически ее границы могут быть обозначены как 1 и 2.

- Определение состава членов бытового мультисервиса. Данная работа является параллельной по отношению к предыдущему и ее границы могут быть обозначены как 3 и 4.

- Создание системы менеджмента качества каждым членом бытового мультисервиса. Границы данной работы могут быть обозначены как 5 и 6.

- Разработка регламента контроля качества услуг бытового мультисервиса. Данная работа является следствием создания системы ме- неджмента качества каждым членом бытового мультисервиса, в связи с чем границы данной работы могут быть обозначены как 6 и 7.

- Создание комиссии по контролю качества услуг бытового мультисервиса. Данный этап является частным в рамках создания системы менеджмента качества каждым членом бытового мультисервиса, следовательно, его границы могут быть обозначены как 8 и 6.

- Разработка регламента оказания услуг социально незащищенным группам населения. Границы данной работы могут быть обозначены как 9 и 10.

- Разработка мер дисциплинарного воздействия на нарушителей регламента контроля качества. Границы данной работы могут быть обозначены как 11 и 12.

- Прекращение деятельности предприятий бытового обслуживания, оказывающих некачественные услуги, в соответствии с положением о бытовом мультисервисе. Данная работа является следствием разработки мер дисциплинарного воздействия на нарушителей регламента контроля качества, в связи с чем границы данной работы могут быть обозначены как 12 и 13.

- Создание координационного совета членов бытового мультисервиса. Данная работа базируется на сформированном составе членов бытового мультисервиса, в связи с чем его границы могут быть обозначены как 4 и 13.

- Разработка правил производственной безопасности оказания бытовых услуг членами бытового мультисервиса. Границы данной работы могут быть обозначены как 14 и 15.

- Разработка правил санитарногигиенической безопасности оказания бытовых услуг. Границы данной работы могут быть обозначены как 16 и 17.

- Разработка условий предоставлений скидок постоянным клиентам. Границы данной работы могут быть обозначены как 18 и 19.

- Проведение анкетирования потребителей. Границы данной работы могут быть обозначены как 20 и 21.

- Разработка мероприятий по предупреждению жалоб потребителей членами бытового мультисервиса. Границы данной работы могут быть обозначены как 22 и 23.

- Разработка мероприятий по предотвращению жалоб на бытовые услуги. Границы данной работы могут быть обозначены как 24 и 25.

- Разработка программы бытового муль- 
тисервиса как центра высокого качества услуг. Границы данной работы могут быть обозначены как 26 и 27.

- Оказание бытовых услуг новым потребителям. Данная работа является следствием разработки программы бытового мультисервиса как центра высокого качества услуг, в связи с чем границы данной работы могут быть обозначены как 27 и 28.

- Оказание бытовых услуг членами мультисервиса постоянным клиентам. Данная работа является следствием разработки условий предоставлений скидок постоянным клиентам, в связи с чем границы данной работы могут быть обозначены как 19 и 28

Системная интеграция приведенных работ позволяет сформировать универсальную сетевую модель создания системы менеджмента качества в мультисервисе. Визуализация данной сетевой модели представлена на рисунке 1.

Следующим этапом методология сетевого планирования является оценка параметров времени, выделенных в рамках сетевой модель создания системы менеджмента качества, работ. В рамках данного исследования для целей реализации данного этапа был выбран экспертных подход. Экспертами в данном случае выступали собственники торгово-развлекательного комплекса. Экспертам предлагалось присвоить каждой из выделенных работ пессимистическую и оптимистическую оценку потенциального времени реализации. Для целей формирования ожидаемой оценки присвоенные экспертами пессимистическая и оптимистическая оценки усреднялись и корректировались на натуральный логарифм от сформированного временного разрыва. Данная корректировка обусловлена относительным приращением риска повышения ожидаемого времени при снижении уровня уверенности экспертов, косвенным признаком чего является повышение разрыва между пессимистической и оптимистической оценкой. Таким образом, ожидаемая оценка времени реализации работ может быть определена в соответствии со следующей формулой:

$T_{i}=\left(1-k_{i}\right) * T_{i_{\text {min }}}+k_{i} * T_{i_{\text {max }}}$

Где:

$k_{i}=\frac{\left(\ln T_{i_{\max }}-T_{i_{\min }}\right)-\left(\ln T_{\min _{\max }}-T_{\min _{\min }}\right)}{\left(\ln T_{\text {max }_{\max }}-T_{\max _{\min }}\right)-\left(\ln T_{\min _{\max }}-T_{\text {min }_{\min }}\right)}$

Где:

$T_{i}$ - ожидаемая оценка времени реализации работы і.

$k_{i}-$ коэффициент риска временного разрыва реализации работы i.

$T_{i_{\max }}-$ оптимистическая оценка времени реализации работы i.

$T_{i_{\min }}-$ пессимистическая оценка времени реализации работы i.

$T_{\max }$ max - максимальная оптимистическая

Принятие решения о создании системы менеджмента качества в мультисервисе

(0)

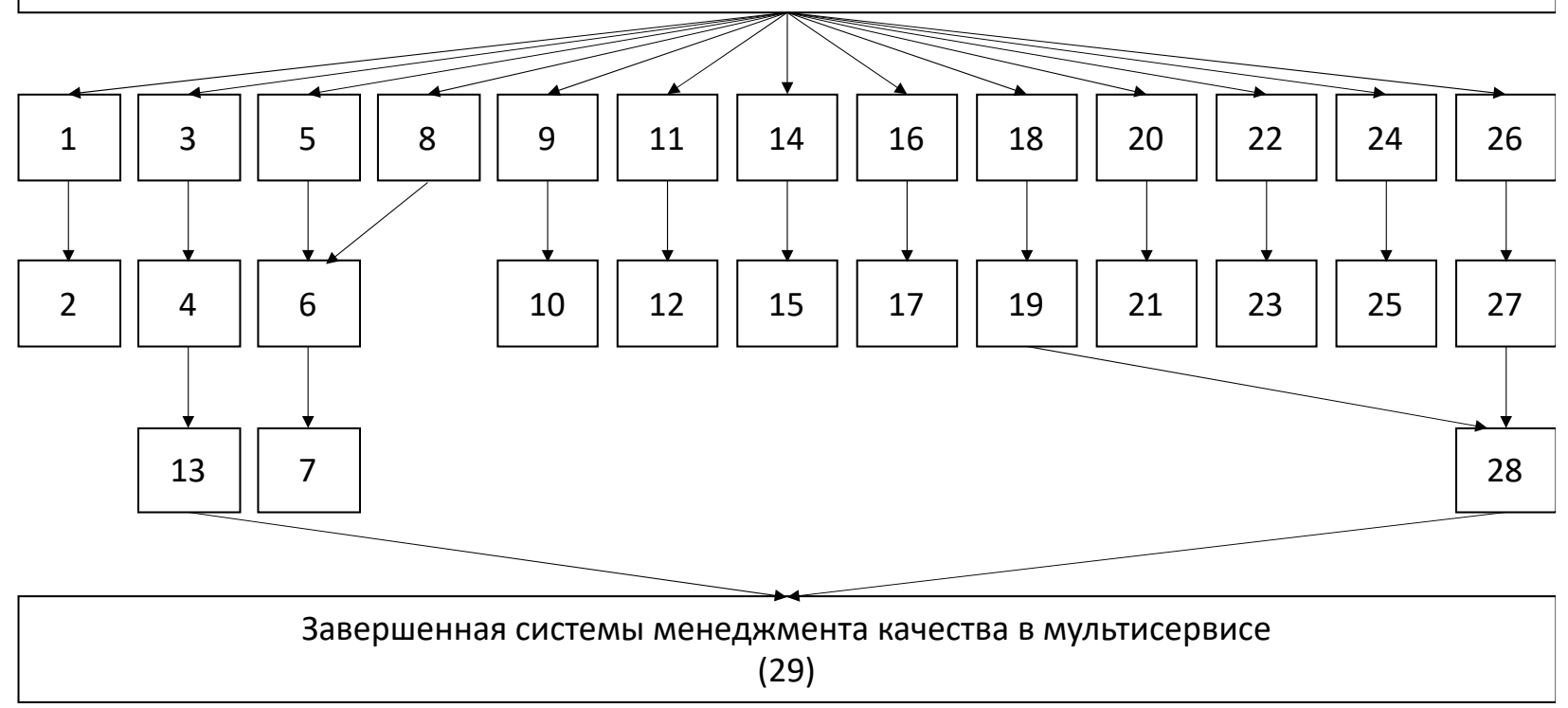

Рисунок 1. Сетевая модель создания системы менеджмента качества в мультисервисе 
оценка времени реализации работ.

$T_{\min _{\max }}-$ минимальная оптимистическая оценка времени реализации работ.

$T_{\text {min }_{\text {min }}}-$ минимальная пессимистическая оценка времени реализации работ.

$T_{\text {max }_{\text {min }}}-$ максимальная пессимистическая оценка времени реализации работ.

Расчеты критического пути проводились на основе предположения, что продолжительность работ по созданию системы менеджмента качества не превысит 5 месяцев. Для конкретизации был принят период с 01.08.2020 по 31.12.2020, что составляет 153 дня. Экспертные оценки времени продолжительности работ представлены в таблице 1.

Как можно судить по данным, представленным в таблице, временной разрыв значительно дифференцирован, в связи с чем оценка ожидаемая оценка времени реализации работ в большей степени стремится $\mathrm{k}$ пессимистическим значениям. Ожидаемая оценка времени работ представлены на рисунке 2.

Таблица 1. Экспертная оценка продолжительности работ

\begin{tabular}{|c|c|c|}
\hline Коды работ & Оптимистическая оценка времени (дни) & Пессимистическая оценка времени (дни) \\
\hline $1-2$ & 3 & 4 \\
\hline $3-4$ & 3 & 5 \\
\hline $4-13$ & 9 & 32 \\
\hline $5-6$ & 13 & 31 \\
\hline $8-6$ & 9 & 18 \\
\hline $6-7$ & 17 & 42 \\
\hline $9-10$ & 6 & 7 \\
\hline $11-12$ & 3 & 5 \\
\hline $12-13$ & 8 & 32 \\
\hline $14-15$ & 3 & 4 \\
\hline $16-17$ & 3 & 4 \\
\hline $18-19$ & 2 & 5 \\
\hline $19-28$ & 9 & 31 \\
\hline $20-21$ & 9 & 31 \\
\hline $22-23$ & 8 & 16 \\
\hline $24-25$ & 5 & 7 \\
\hline $26-27$ & 2 & 5 \\
\hline $27-28$ & 8 & 32 \\
\hline
\end{tabular}

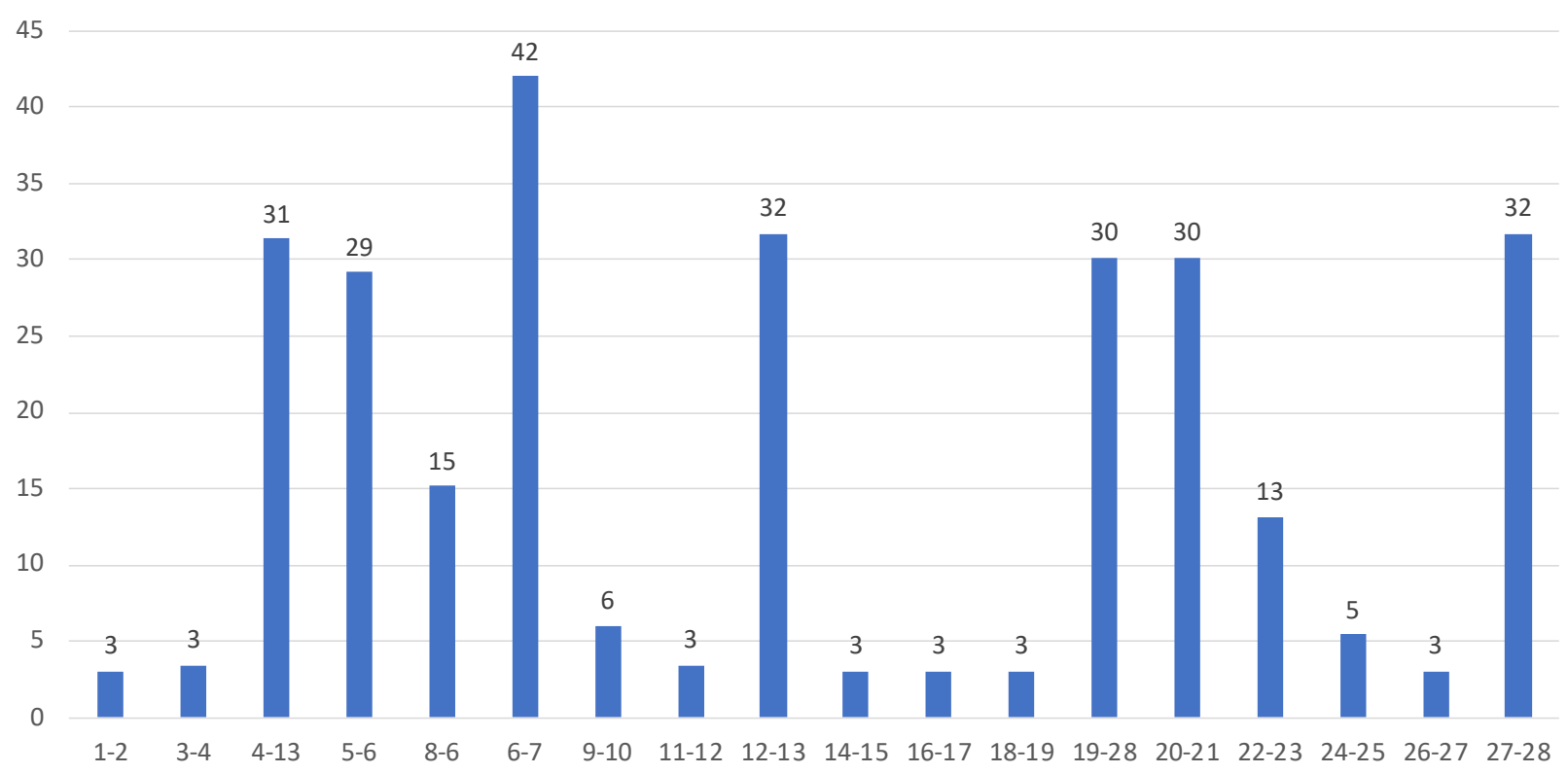

Рисунок 2. Ожидаемая оценка времени работ 
Параметры сетевой модели рассчитывались в соответствии со стандартным алгоритмом. Ранний возможный срок наступлений событий $\left(T_{l}^{p}\right)$ - это минимальный из возможных моментов наступления данного события при заданных продолжительностях работ и начальном моменте без учета директивного срока завершения комплекса работ. Результаты расчета данного параметра представлены в таблице 2 .

Поздний допустимый срок наступления $\left(T_{i}^{\Pi}\right)$ - это максимальный из допустимых моментов наступления данного события, при котором еще возможно выполнение всех последующих работ с соблюдением раннего срока наступления завершающего события (или с соблюдением директивного срока, если он задан). Результаты расчета данного параметра представлены в таблице 3.

В соответствии с выполненными расчетами критическое время, равное раннему сроку наступления завершающего события, составляет 93 дня. Оптимизация сетевой модели в данном случае не требуется, так как критическое время составляет 93 дня, в то время как директивное

Таблица 2. Ранний срок наступления событий

\begin{tabular}{|c|c|c|c|}
\hline \multicolumn{2}{|c|}{ Коды работ } & \multirow{2}{*}{$\begin{array}{c}\text { Ожидаемая продолжительность } \\
\text { работы (дни) }\end{array}$} & \multirow{2}{*}{$\begin{array}{l}\text { Ранний срок наступления } \\
\text { (дни) }\end{array}$} \\
\hline Работа i & Работа ј & & \\
\hline 0 & 1 & 0 & 0 \\
\hline 1 & 2 & 3 & 3 \\
\hline 0 & 3 & 0 & 0 \\
\hline 3 & 4 & 3 & 3 \\
\hline 0 & 5 & 0 & 0 \\
\hline 5 & 6 & 29 & \multirow{2}{*}{15} \\
\hline 8 & 6 & 15 & \\
\hline 6 & 7 & 42 & 67 \\
\hline 0 & 8 & 0 & 0 \\
\hline 0 & 9 & 0 & 0 \\
\hline 9 & 10 & 6 & \multirow{2}{*}{67} \\
\hline 7 & 10 & 0 & \\
\hline 0 & 11 & 0 & 0 \\
\hline 11 & 12 & 3 & \multirow{2}{*}{67} \\
\hline 10 & 12 & 0 & \\
\hline 0 & 14 & 0 & 0 \\
\hline 16 & 17 & 3 & \multirow{2}{*}{3} \\
\hline 15 & 17 & 0 & \\
\hline 0 & 18 & 0 & 0 \\
\hline 20 & 21 & 30 & 30 \\
\hline 0 & 22 & 0 & 0 \\
\hline 22 & 23 & 13 & 13 \\
\hline 0 & 24 & 0 & 0 \\
\hline 24 & 25 & 5 & \multirow{3}{*}{5} \\
\hline 21 & 25 & 0 & \\
\hline 23 & 25 & 0 & \\
\hline 0 & 26 & 0 & 0 \\
\hline 26 & 27 & 3 & 3 \\
\hline 4 & 13 & 31 & \multirow{2}{*}{93} \\
\hline 12 & 13 & 32 & \\
\hline 19 & 28 & 30 & \multirow{2}{*}{35} \\
\hline 27 & 28 & 32 & \\
\hline 13 & 29 & 0 & \multirow{2}{*}{93} \\
\hline 28 & 29 & 0 & \\
\hline
\end{tabular}




\section{Таблица 3. Поздний срок наступления событий}

\begin{tabular}{|c|c|c|c|}
\hline \multicolumn{2}{|c|}{ Коды выходящих работ } & \multirow{2}{*}{$\begin{array}{c}\text { Ожидаемая продолжительность } \\
\text { работы (дни) }\end{array}$} & \multirow{2}{*}{$\begin{array}{c}\text { Поздний срок наступления } \\
\text { (дни) }\end{array}$} \\
\hline Работа ј & Работа r & & \\
\hline 29 & & & 93 \\
\hline 28 & 29 & 0 & 93 \\
\hline 27 & 28 & 32 & 61 \\
\hline 26 & 27 & 3 & 58 \\
\hline 25 & 27 & 0 & 52 \\
\hline 24 & 25 & 5 & 47 \\
\hline 23 & 25 & 0 & 52 \\
\hline 22 & 23 & 13 & 39 \\
\hline 21 & 25 & 0 & 52 \\
\hline 20 & 21 & 21 & 31 \\
\hline 19 & 28 & 21 & 52 \\
\hline 18 & 19 & 3 & 49 \\
\hline 17 & 19 & 0 & 52 \\
\hline 16 & 17 & 3 & 49 \\
\hline 15 & 17 & 0 & 52 \\
\hline 14 & 15 & 3 & 46 \\
\hline 13 & 29 & 0 & 93 \\
\hline 12 & 13 & 32 & 61 \\
\hline 11 & 12 & 3 & 58 \\
\hline 10 & 12 & 0 & 61 \\
\hline 9 & 10 & 6 & 55 \\
\hline 8 & 6 & 15 & 12 \\
\hline 7 & 10 & 0 & 61 \\
\hline 6 & 7 & 42 & 34 \\
\hline 5 & 6 & 29 & 0 \\
\hline 4 & 13 & 31 & 61 \\
\hline 3 & 4 & 3 & 58 \\
\hline 2 & 4 & 0 & 58 \\
\hline 1 & 2 & 3 & 55 \\
\hline \multirow{13}{*}{0} & 1 & 0 & \multirow{13}{*}{0} \\
\hline & 3 & 0 & \\
\hline & 5 & 0 & \\
\hline & 8 & 0 & \\
\hline & 9 & 0 & \\
\hline & 11 & 0 & \\
\hline & 14 & 0 & \\
\hline & 16 & 0 & \\
\hline & 18 & 0 & \\
\hline & 20 & 0 & \\
\hline & 22 & 0 & \\
\hline & 24 & 0 & \\
\hline & 26 & 0 & \\
\hline
\end{tabular}


время, за которое должен быть полностью выполнен весь комплекс работ по созданию менеджменту качества, составляет 153 дня.

В завершении необходимо определить критический путь по созданию системы менеджмента качества и параметры сетевой модели. В соответствии с графом, представленным на рисунке 3.3.1, критический путь образует следующая совокупность работ:

- Создание системы менеджмента качества каждым членом бытового мультисервиса. Как было определено ранее, границы данной работы могут быть обозначены как 5 и 6.

- Разработка регламента контроля качества. Границы данной работы могут быть обозначены как 6 и 7.

- Прекращение деятельности предприятий бытового обслуживания, в соответствии с положением о бытовом мультисервисе. Границы данной работы могут быть обозначены как 12 и 13.
Следовательно, данные организационные аспекты деятельности бытового мультисервиса должны быть учтены в договоре аренды, заключаемом между собственником ТРК и предпринимателями, оказывающими бытовые услуги. В раздел договора «Обязанности арендатора» целесообразно включить следующие условия:

- Арендатор обязуется разработать систему менеджмента качества бытовых услуг.

- Арендатор обязывается вступить в члены координационного совета бытового мультисервиса и выполнять все требования регламента контроля качества бытового мультисервиса.

В раздел «Особые условия» целесообразно включить следующее условие: «Действия арендного договора прекращается досрочно в случае получения арендодателем представления комиссии по контролю качества бытового мультисервиса».

\section{Библиографический список}

1. Азаренко Н.Ю., Баланюк Л. А. Инновационные технологии в стратегическом управлении предприятием. В сборнике: Актуальные аспекты управления и экономики в современных условиях. Сборник материалов IX Всероссийского молодежного научного форума. 2017. С. 111-114.

2. Герасимова Е.А., Чаплина А. Н. Методика оценки уровня стратегического развития организаций сферы услуг // Стратегия предприятия в контексте повышения его конкурентоспособности. - 2020. - № 9. - С. 196-200.

3. Гериик Ю.Г., Кайдалов С.А. Метрологический менеджмент и управление качеством как факторы, способствующие переходу предприятий медицинской промышленности на инновационную модель развития // Вестник Росздравнадзора. 2011. № 5. С. 42-45.

4. Гордиенко А.В., Руденко О.Н. Исследование рынка сферы услуг и присущих данной сфере рисков // Актуальные вопросы современной экономики. - 2019. - № 3-1.- С. 786-794.

5. Домнин А.Д., Барыкин С.Е. Разработка сетевой модели управления качеством бытовых услуг // Экономические науки. 2020. № 191. С. 70-81.

6. Домнин А.Д., Князев А.С., МакароваЮ.Н., Макарова О.Н. Теоретические аспекты инновации в научнотехническом прогрессе // В сборнике: Стратегии и инструменты управления экономикой: отраслевой и региональный аспект. Материалы VIII Международной научно-практической конференции. Санкт-Петербург, 2019. С. $258-261$.

7. Дробышев В.В. Формирование государственных минимальных стандартов и нормативов для регулирования качества социально значимых услуг // Вестник Тамбовского университета. Серия: Гуманитарные науки. 2007. № $12-2$.

8. Дышловой И.Н., Стренадо А. Д. Теоретические аспекты формирования управленческих структур в сфере услуг // Kant. - 2020. - № 1 (34). - С. 54-62.

9. Забелин Б.Ф., Конников Е. А., Никишин В. М., Хатанзейский К. К. Методология формирования системы производственного менеджмента // Экономические науки. 2019. № 177. С. 51-55.

10. Забелин Б.Ф., Конников Е. А., Никишин В. М., Хатанзейский К. К., Дробинцева Д. Ф. Интегрированная система планирования и управления реализацией проектов // Экономические науки. 2020. № 185. С. 111-114.

11. Окрепилов В.В. Менеджмент качества: учебник // СПб.: Изд-во Политехн. ун-та. 2013.

12. Плотникова E. В. Принятие региональных управленческих рещений на основе оценки качества жилищного фонда [Текст]/ Е. В.Плотникова// Образование. Экономика. Общество. - 2015. - No 5-6 (49-50). - С. 52-56.

13. Родионов Д.Г. Регулирование развития сферы услуг в крупнейших городах в условиях трансформирования российской экономики (на примере городов Москвы и Санкт-Петербурга): дис.- Российский государственный университет сервиса, 2004. [Электронный ресурс].URL: http://dlib.rsl.ru/rsl01002000000/rsl01002624000/ rs101002624979/rs101002624979.pdf (Дата доступа 07.02.2020). 